\title{
cmaJOPEN
}

\section{Association between continuity and access in primary care: a retrospective cohort study}

\author{
Lisa L. Cook PhD, Richard P. Golonka MSc, Charles M. Cook PhD, Robin L. Walker PhD, \\ Peter Faris PhD, Shannon Spenceley RN PhD, Richard Lewanczuk MD PhD, Robert Wedel MD, \\ Rebecca Love BSc, Cheryl Andres MSc, Susan D. Byers MD, Tim Collins MD, Scott Oddie PhD
}

\section{Abstract}

Background: Continuity of care is a tenet of primary care. Our objective was to explore the relation between a change in access to a primary care physician and continuity of care.

Methods: We conducted a retrospective cohort study among physicians in a primary care network in southwest Alberta who measured access consistently between 2009 and 2016. We used time to the third next available appointment as a measure of access to physicians. We calculated the provider and clinic continuity, discontinuity and emergency department use based on the physicians' own panels. Physicians who improved, worsened or maintained their level of access within a given year were assessed in multilevel models to determine the association with continuity of care at the physician and clinic levels and the emergency department.

Results: We analyzed data from 190 primary care physicians. Physicians with improved access increased provider continuity by $6.8 \%$ per year, reduced discontinuity by $2.1 \%$ per year, and decreased emergency department encounters by 78 visits per 1000 patients per year compared to physicians with stable access. Physicians with worsening access had a $6.2 \%$ decrease in provider continuity and an increased number of emergency department encounters (64 visits per 1000 panelled patients per year) compared to physicians with stable access.

Interpretation: Changes in access to primary care can affect whether patients seek care from their own physician, from another clinic or at the emergency department. Improving access by reducing the delay in obtaining an appointment with one's primary care physician may be one mechanism to improve continuity of care.

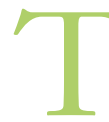
he province of Alberta, Canada, is transforming its health care system, moving from a focus on acute care services to an emphasis on care in the community that meets the health and social needs of its population. ${ }^{1}$ An important aspect of community-based care is the patient's medical home, where most care is led by a consistent primary care provider. This concept, known as continuity of care, was highlighted decades ago, ${ }^{2}$ and mechanisms to support information exchange and disease management within an interpersonal relationship make continuity of care a tenet of primary care. ${ }^{3}$ Studies have shown that patients with high continuity of care with a single provider have better outcomes, such as fewer hospital admissions ${ }^{4-11}$ and emergency department encounters, ${ }^{12-16}$ improved delivery of preventive care services, ${ }^{17-20}$ increased adherence to medications ${ }^{21-23}$ and enhanced satisfaction, ${ }^{24,25}$ as well as lower costs. ${ }^{9,26,27}$

Access to primary care is about a patient's opportunity to receive timely, appropriate and quality health care services. ${ }^{28}$
It is widely agreed that the opportunity for a patient to receive care when needed is associated with better patient and system outcomes. ${ }^{29}$ To our knowledge, the question of precisely how delaying primary care intersects with continuity of care has not been examined empirically. Benett ${ }^{30}$ postulated that continuity of care and access to primary care were not independent concepts. Intuitively, if the delay in access to one's own physician is too great from the patient's perspective, it follows that the patient may seek care from another physician and place continuity of care in peril, or, worse, seek care in the emergency department. Other jurisdictions have

Competing interests: None declared.

This article has been peer reviewed.

Correspondence to: Lisa Cook, Lisa.Cook@ahs.ca

CMAJ Open 2020. DOI:10.9778/cmajo.20200014 
shown that when timely access to primary care is mandated by government bodies, continuity of care with the patient's physician decreases. ${ }^{31}$

The connection between primary care access (i.e., the length of time a patient waits for an appointment with his or her physician) and continuity of care is complex. We designed this study to explore the relation between the 2 concepts by selecting a group of physicians who measured access consistently over a period of 8 years and determining where their patients sought care when access changed.

\section{Methods}

\section{Study design and setting}

We conducted a retrospective observational cohort study to explore the association between primary care access and continuity of care outcomes of 205 primary care physicians participating in the Chinook Primary Care Network in Alberta from 2009 to 2016. The Chinook Primary Care Network, which was established in 2005, serves an urban centre of 100000 and 12 small rural communities in southwest Alberta. Primary care networks in Alberta are the common model of primary care delivery consisting of physicians and allied health care professionals delivering care in their communities. ${ }^{32}$ The Chinook Primary Care Network was an early adopter of office practice design concepts, ${ }^{33}$ learning to measure delay for physician appointments and balancing patient demand with physician supply; data were collected regularly for improvement purposes. Additional information about the Chinook Primary Care Network and its adoption of office practice redesign concepts can be found in Appendix 1 (available at www.cmajopen.ca/content/8/4/E722/suppl/DC1).

\section{Study cohort}

For each year of the study, network physicians were included in the cohort if they had a physician panel and at least 13 measures of access. A physician panel is a list of patients for whom the physician was the most responsible provider of continuous and longitudinal primary health care. Physicians reviewed their panels annually and reconfirmed their most responsible provider status with their patients (e.g., attachment). ${ }^{34} \mathrm{We}$ extracted panels from 2009 to 2016 from the physician's electronic medical record, which represented the panel of the physician for a specific year (e.g., the physician panel for 2011 was extracted from the electronic medical record on Jan. 1, 2012, and used to assess the activity of that physician's patients for 2011).

We measured primary care access using the third next available (TNA) appointment ${ }^{35}$ metric, which is the delay patients experience accessing providers for a scheduled short appointment (typically 10-15 $\mathrm{min}$ in duration, for routine primary care encounters). A TNA value of 0 indicates that a patient could have a same-day appointment, whereas a TNA value of 14 indicates that a patient would experience a 2 -week delay to get an appointment. Third next available appointments for short appointments were recorded in an online database at the same time on Tuesdays by clinic staff; there- fore, a week was defined as starting on Tuesday and extending to the following Monday. We recorded the TNA measures for each physician between Jan. 5, 2009, and Jan. 2, 2017. Thirteen TNA measures represented at least 1 measure of TNA appointments each month. Most physicians had more than 43 weekly TNA measures each year.

\section{Outcome measures}

Our goal was to associate the weekly TNA value throughout a year directly with the activity of the panelled patients. Therefore, we matched each physician panel to the Alberta Health Practitioner Claims database to determine the number of visits these patients made to a clinic each week. From our previous example, the physician panels for 2011 were matched to the primary care encounters that occurred in 2011. This step ensured that we could link the activity of the physician's panel directly to the TNA measure on a weekly basis. Patient activity was linked to 1 encounter rather than multiple claims; therefore, we defined 1 visit as the same patient seeing the same physician in the same clinic on the same day. We tabulated the weekly number of visits the panelled patients made to their physician (using the same definition of "week" as used for the TNA metric) and divided it by the total number of weekly primary care visits. This calculation equalled the provider continuity and is based on the Known Provider Continuity Index. ${ }^{36}$

We also calculated a weekly clinic continuity outcome, taking the weekly number of visits the panelled patients made to other physicians within the clinic and dividing it by the total weekly primary care visits. We further calculated a weekly discontinuity outcome by taking the number of visits the panelled patients made to a physician at another clinic and dividing it by the total number of primary care visits. We matched the clinics to the Alberta Health Services Distance and DriveTime Look-Up map and included only visits to clinics that were within a $50-\mathrm{km}$ driving radius of where the panelled physician was located. ${ }^{37}$ More detailed methodology on the continuity measures can be found in Appendix 1 .

We also linked the panels for each physician to the National Ambulatory Care Reporting System, which is used in Canada for collecting and reporting on all levels of ambulatory care including that provided at emergency departments. Only nonscheduled visits to emergency departments and urgent care centres were included. We defined 1 emergency department encounter as a visit by a panelled patient to an emergency department within a $50-\mathrm{km}$ driving radius of the panelled physician's location. ${ }^{37}$ We then calculated a weekly emergency department encounter outcome, using the same definition of week described above.

\section{Confounding variables}

We selected physician practice and panel variables that have been shown to influence appointment delay and continuity $^{6,38-47}$ (Table 1). We also calculated the starting TNA value as a confounding variable to assess whether having a higher starting value influenced the outcome of interest by taking the average of the first 3 TNA measures. 


\begin{tabular}{|ll|}
\hline Table 1: Practice- and panel-level confounding variables \\
\hline Practice & \multicolumn{1}{c|}{ Panel } \\
\hline No. of physicians in the clinic ${ }^{6,38}$ & Physician panel size $^{39,40}$ \\
\hline Gender of physicians ${ }^{41,42}$ & Age of panel $^{39}$ \\
\hline Location of clinic ${ }^{43}$ & $\begin{array}{l}\text { No. of patients on multiple } \\
\text { panels }^{44}\end{array}$ \\
\hline No. of days worked per week $^{45}$ & Panel complexity $^{* 39,46}$ \\
\hline & No. of female patients \\
\hline
\end{tabular}

\section{Statistical analysis}

We assessed physicians' weekly appointment delay and continuity outcomes in 1-year segments (January to December). We conducted a series of linear regressions to identify physicians with appointment delays that improved (statistically significant negative trajectory, $p<0.05$ ), worsened (statistically significant positive trajectory, $p<0.05$ ) or remained stable (not statistically significant, $p \geq 0.05$ ) for each year of the study. Grouping the physicians in this manner created 3 TNA trajectory categories (improved, worsened, stable).
We used nested multilevel mixed-effects regression models to assess the relation between the continuity of care outcomes (provider and clinic continuity, discontinuity and emergency department visits) and annual TNA changes, and adjusted for potential confounding patient and physician factors. We examined physician and clinic variations using multilevel mixed-effect regression models with physician nested by year and week. We determined components of variation in the multilevel model by intraclass correlation, which, in our study, meant examining the ratio of variance within each level of our model (weekly TNA measures, physicians and year).

We examined the association between TNA trajectory categories and the weekly continuity trajectory using a group-bytime interaction. The model included a random intercept for each physician within a given year. In this way, our study design allowed us to estimate how continuity changed when physicians' appointment delays improved, worsened or stayed the same, after adjusting for relevant confounders and accounting for the association among observations within physicians in a given year. A visual representation of the model is provided in Figure 1. We created scatterplots for each TNA trajectory category to visualize the relation with the continuity of care outcomes without adjustment of any factors. This step satisfied our assumption of common support.

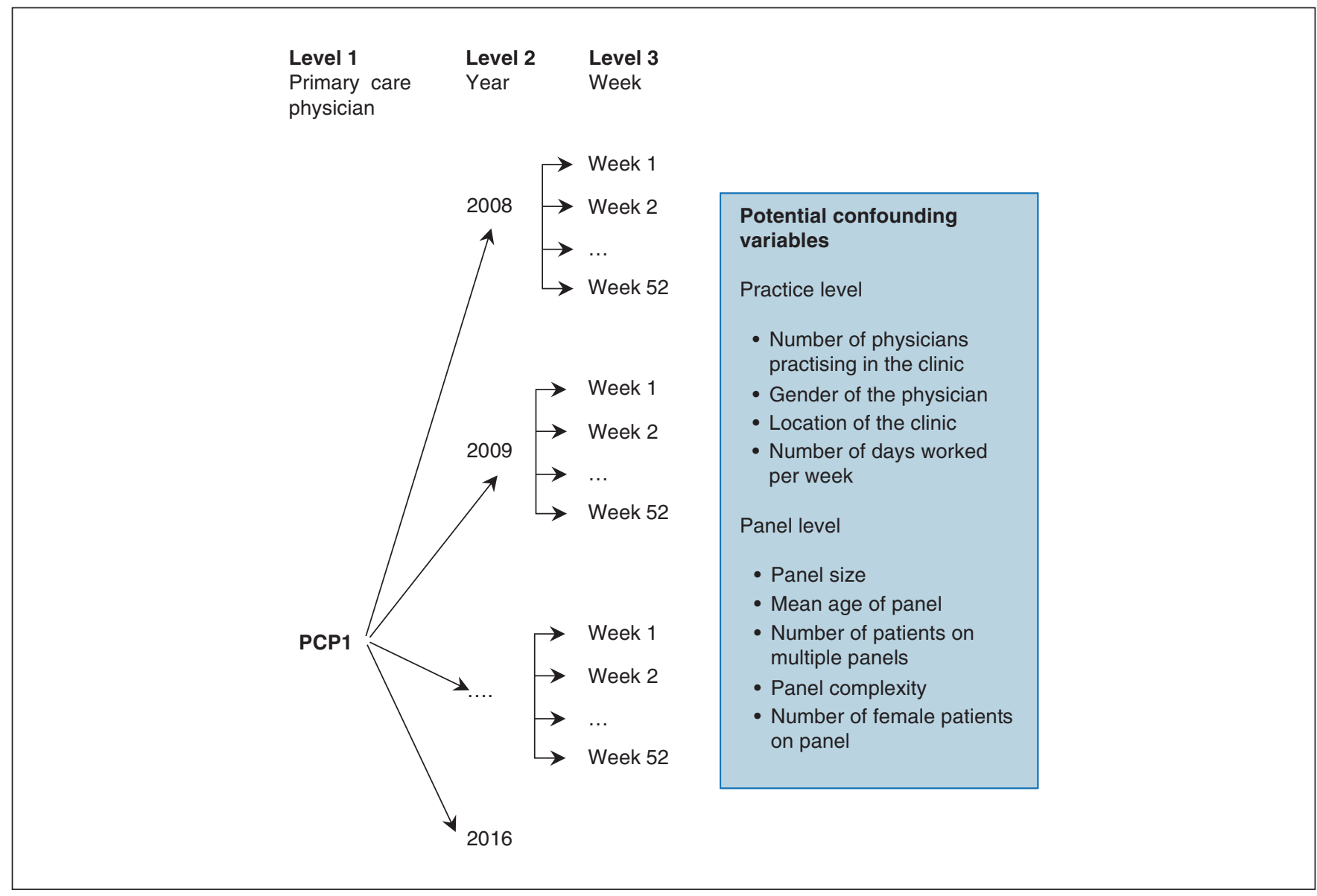

Figure 1: Multilevel model focused on primary care physicians (PCPs), measuring weekly access each year of the study. Week of the access measure was nested in the year for each PCP (example shown for 1 physician), with adjustment for potential confounding patient and physician factors. 
We performed all statistical analysis using Stata version 13.1 (StataCorp).

\section{Ethics approval}

This study was approved by the University of Alberta Health Research Ethics Board 3.

\section{Results}

Of the 205 physicians, 190 met our inclusion criteria ( $\geq 13$ weekly measures of TNA in a calendar year) (Table 2 ). The number of physicians increased annually between 2009 and 2016 (from 81 to 133), which led to a corresponding increase in the number of panelled patients each year (from 110868 to 169653 ). The number of clinics and the number of physicians per clinic increased over the first 3 years of the study, whereas the proportion of female physicians remained stable, and the proportion of rural physicians decreased. The panel size, mean age, complexity, female composition and representation of older patients all remained consistent over the study period. There was a decrease in the overall proportion of patients present on multiple physician panels (from 15410 [13.9\%] to 19330 [11.4\%]) (Table 2).

Overall, the 4 outcome variables appeared relatively stable year upon year when viewed at the aggregate level (Table 3).

The majority of physicians had appointment delay and continuity outcomes for more than 1 year during the 8 -year study period. Of the 872 annual TNA trajectories, $96(11.0 \%)$ improved, $669(76.7 \%)$ remained stable and $107(12.3 \%)$ worsened. We combined weeks for each year of the study period to depict each of the average weekly outcome measures segmented by the TNA exposure groups (Figure 2). We then applied a linear regression line to each scatterplot.

For physicians with an improved annual TNA trajectory, provider continuity $\left(\beta=0.21, p<0.001, R^{2}=34.0 \%\right)$ and clinic continuity $\left(\beta=0.06, p<0.001, R^{2}=35.1 \%\right)$ increased,

Table 2: Descriptive statistics for confounding variables for each study year

\begin{tabular}{|c|c|c|c|c|c|c|c|c|}
\hline \multirow[b]{2}{*}{ Variable } & \multicolumn{8}{|c|}{ Year; mean $\pm S D^{*}$} \\
\hline & 2009 & 2010 & 2011 & 2012 & 2013 & 2014 & 2015 & 2016 \\
\hline $\begin{array}{l}\text { No. of physicians with a } \\
\text { panel }\end{array}$ & 86 & 93 & 119 & 119 & 130 & 152 & 154 & 153 \\
\hline $\begin{array}{l}\text { No. of physicians excluded } \\
\text { ( }<13 \text { TNA measures } \\
\text { within the year) }\end{array}$ & 5 & 2 & 22 & 3 & 16 & 38 & 28 & 20 \\
\hline $\begin{array}{l}\text { No. of physicians included } \\
\text { in analysis }\end{array}$ & 81 & 91 & 97 & 116 & 114 & 114 & 126 & 133 \\
\hline \multicolumn{9}{|l|}{ Confounding variables } \\
\hline \multicolumn{9}{|l|}{ Practice characteristics } \\
\hline No. of physicians & 81 & 91 & 97 & 116 & 114 & 114 & 126 & 133 \\
\hline No. of clinics & 17 & 18 & 19 & 24 & 23 & 21 & 22 & 23 \\
\hline $\begin{array}{l}\text { Female physicians, no. } \\
(\%)\end{array}$ & $21(25.9)$ & $27(29.7)$ & $30(30.9)$ & $33(28.4)$ & $37(32.5)$ & $32(28.1)$ & $39(31.0)$ & $40(30.1)$ \\
\hline $\begin{array}{l}\text { Rural physicians, no. } \\
(\%)\end{array}$ & $47(58.0)$ & $51(56.0)$ & $53(54.6)$ & $54(46.6)$ & $53(46.5)$ & $57(50.0)$ & $58(46.0)$ & $65(48.9)$ \\
\hline $\begin{array}{l}\text { No. of days worked per } \\
\text { week }\end{array}$ & $4.0 \pm 1.5$ & $4.0 \pm 1.5$ & $3.9 \pm 1.5$ & $4.0 \pm 1.5$ & $4.0 \pm 1.4$ & $4.1 \pm 1.3$ & $4.0 \pm 1.4$ & $3.9 \pm 1.4$ \\
\hline $\begin{array}{l}\text { No. of physicians per } \\
\text { clinic }\end{array}$ & $7.1 \pm 3.4$ & $7.3 \pm 3.6$ & $8.2 \pm 4.5$ & $8.7 \pm 4.1$ & $7.9 \pm 3.9$ & $9.5 \pm 5.0$ & $8.4 \pm 3.5$ & $7.9 \pm 3.4$ \\
\hline \multicolumn{9}{|l|}{ Panel characteristics } \\
\hline No. of panelled patients & 110868 & 114531 & 108244 & 151866 & 157631 & 158974 & 164965 & 169563 \\
\hline Physician panel size & $1458.8 \pm 779$ & $1286.9 \pm 742$ & $1127.5 \pm 674$ & $1368.2 \pm 928$ & $1382.7 \pm 832$ & $1406.8 \pm 845$ & $1330.4 \pm 829$ & $1367.4 \pm 806$ \\
\hline Age of patients, $y r$ & $39.6 \pm 6.8$ & $40.1 \pm 7.2$ & $40.4 \pm 7.3$ & $40.3 \pm 6.8$ & $40.1 \pm 6.5$ & $40.0 \pm 6.1$ & $39.1 \pm 5.8$ & $39.2 \pm 6.0$ \\
\hline $\begin{array}{l}\text { Patients on multiple } \\
\text { panels, \% }\end{array}$ & $13.9 \pm 6.9$ & $13.4 \pm 7.7$ & $14.1 \pm 10.9$ & $12.5 \pm 7.1$ & $14.0 \pm 7.5$ & $11.5 \pm 5.9$ & $12.0 \pm 8.9$ & $11.4 \pm 8.3$ \\
\hline Complex patients, $\%$ & $5.2 \pm 1.8$ & $5.0 \pm 1.7$ & $5.6 \pm 1.8$ & $5.3 \pm 1.7$ & $4.8 \pm 1.9$ & $5.1 \pm 1.7$ & $5.3 \pm 1.8$ & $6.0 \pm 2.0$ \\
\hline Female patients, $\%$ & $55.2 \pm 13.5$ & $55.5 \pm 13.8$ & $55.2 \pm 14.4$ & $55.3 \pm 13.4$ & $54.2 \pm 13.2$ & $53.5 \pm 12.6$ & $53.6 \pm 12.4$ & $53.1 \pm 11.9$ \\
\hline $\begin{array}{l}\text { Patients aged > } 60 \mathrm{yr}, \\
\%\end{array}$ & $21.3 \pm 9.7$ & $22.4 \pm 10.5$ & $22.4 \pm 10.8$ & $23.5 \pm 10.3$ & $23.1 \pm 10.0$ & $22.7 \pm 9.4$ & $22.3 \pm 8.8$ & $22.9 \pm 9.4$ \\
\hline
\end{tabular}




\section{Research}

\begin{tabular}{|l|lcccccc|}
\hline \multicolumn{1}{l}{ Table 3: Means of the outcome variables for each year of the study period } \\
\hline
\end{tabular}

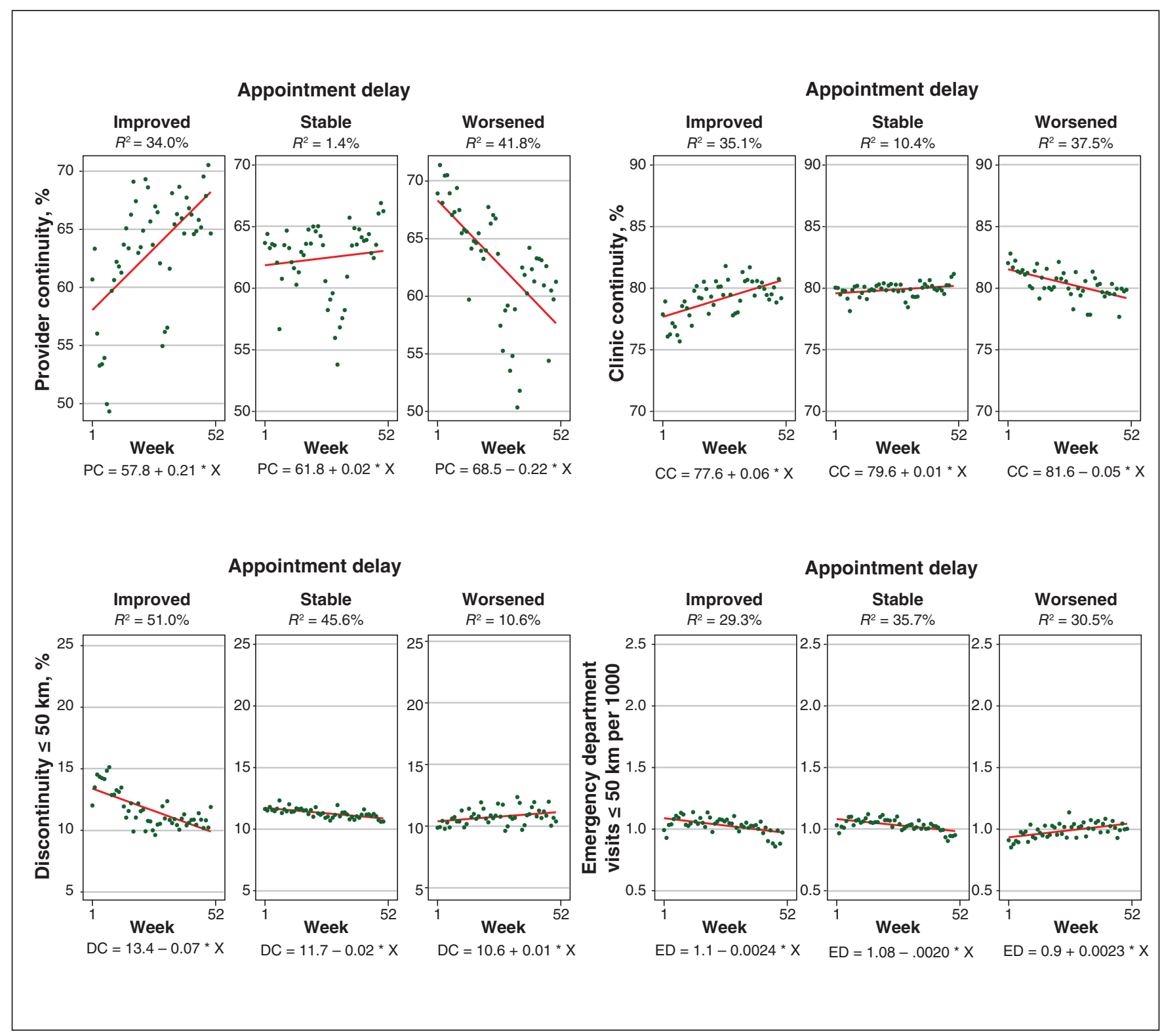

Figure 2: Scatterplot and linear regression of average weekly outcome measures within each third next available appointment exposure group. Note: $\mathrm{CC}=$ clinic continuity, $\mathrm{DC}=$ discontinuity, $\mathrm{ED}=$ emergency department, $\mathrm{PC}=$ provider continuity. 
whereas discontinuity $\left(\beta=-0.07, p<0.001, R^{2}=51.0 \%\right)$ and emergency department visit rates $\left(\beta=-0.002, p<0.001, R^{2}=\right.$ 29.3\%) decreased (Figure 2).

When the annual TNA trajectories worsened, provider continuity $\left(\beta=-0.22, p<0.001, R^{2}=41.8 \%\right)$ and clinic continuity $\left(\beta=-0.05, p<0.001, R^{2}=37.5 \%\right)$ decreased, whereas discontinuity $\left(\beta=0.01, p<0.001, R^{2}=10.6 \%\right)$ and emergency department visit rates $\left(\beta=0.002, p<0.001, R^{2}=30.5 \%\right)$ increased.

When the TNA trajectories remained stable, provider continuity $\left(\beta=0.02, p=0.4, R^{2}=1.4 \%\right)$ did not change; clinic continuity $\left(\beta=0.01, p<0.05, R^{2}=10.4 \%\right)$ and discontinuity $\left(\beta=13.4, p<0.001, R^{2}=45.6 \%\right)$ increased, and the emergency department visit rate decreased $(\beta=-0.002, p<0.001$, $R^{2}=35.7 \%$ ).

With the exception of the starting TNA variable, the confounding variables were balanced across the 3 TNA exposure groups (Table 4). We stratified the starting TNA values into 3 groups ( $<5 \mathrm{~d}, 5-10 \mathrm{~d}$ and $>10 \mathrm{~d})$ to explore the impact on the outcome variables and found it affected the degree of change in continuity over time but not the direction of effect.

All confounding variables were included in each of the 4 separate multilevel regression models, 1 for each outcome of interest. The key output within each was the difference in adjusted outcome trajectories during 1 year when TNA improved or worsened compared to when TNA was stable. The $\beta$ coefficients and $95 \%$ confidence intervals for each outcome variable by TNA exposure are presented in Table 5. The full model outputs, including the intraclass correlation, are summarized in Appendix 1, Supplemental Table S3.

Physicians who improved their TNA over a 1-year period achieved improvements in provider continuity, discontinuity and emergency department use by their panelled patients as compared to physicians with stable TNA. They saw an improvement in provider continuity of $6.8 \%(0.13 \times 52 \mathrm{wk})$ per year $(p<0.001)$, reduced discontinuity of $2.1 \%(0.04 \times$ $52 \mathrm{wk}$ ) per year and fewer emergency department visits, by 78 visits per 1000 panelled patients per year $(1.5 \times 52 \mathrm{wk})$ $(p<0.05)$ (Table 5). There was no change in clinic continuity $(p=0.2)$.

In the group of physicians among whom TNA worsened over the year, provider continuity decreased by $6.2 \%(-0.12 \times$ $52 \mathrm{wk}$ ) per year as compared to physicians whose TNA was stable $(p<0.001)$ (Table 5$)$. There was no change in clinic continuity $(p=0.2)$ or discontinuity $(p=0.4)$. Emergency department visits increased by 64 visits per 1000 panelled patients per year $(1.2 \times 52 \mathrm{wk})(p<0.1)$ compared to physicians with stable TNA.

\section{Interpretation}

When physicians improved their appointment delay, provider continuity increased, patients' attendance with external providers was lower, and patients' use of the emergency department decreased. The opposite result - decreased provider continuity and increased emergency department use was found when physicians worsened their availability to their patients.

Our findings support the following observations on the impact of appointment delay on continuity of care. When faced with a delay for an appointment, patients chose to break their continuity of care with their attached physician and seek care at another clinic or in the emergency department. Although we are unable to claim a causal link between

\begin{tabular}{|c|c|c|c|}
\hline \multirow[b]{2}{*}{ Variable } & \multicolumn{3}{|c|}{ TNA exposure group; mean $\pm \mathrm{SD}^{*}$} \\
\hline & $\begin{array}{c}\text { Improved } \\
n=96\end{array}$ & $\begin{array}{c}\text { Stable } \\
n=669\end{array}$ & $\begin{array}{l}\text { Worsened } \\
n=107\end{array}$ \\
\hline \multicolumn{4}{|l|}{ Practice characteristics } \\
\hline Female physicians, no. (\%) & $38(39.6)$ & $186(27.8)$ & $37(34.6)$ \\
\hline Rural physicians, no. (\%) & $49(51.0)$ & $338(50.5)$ & $51(47.7)$ \\
\hline No. of days worked per week & $4.1 \pm 1.4$ & $4.0 \pm 1.4$ & $4.0 \pm 1.4$ \\
\hline No. of physicians per clinic & $8.8 \pm 4.3$ & $8.0 \pm 4.0$ & $8.0 \pm 3.9$ \\
\hline \multicolumn{4}{|l|}{ Panel characteristics } \\
\hline Physician panel size & $1412.8 \pm 934.4$ & $1388.1 \pm 791.7$ & $1363.3 \pm 938.2$ \\
\hline Age of panel, yr & $39.2 \pm 5.3$ & $40.0 \pm 6.6$ & $39.2 \pm 6.9$ \\
\hline Patients on multiple panels, $\%$ & $13.3 \pm 7.8$ & $13.1 \pm 8.4$ & $12.4 \pm 8.4$ \\
\hline Complex patients, $\%$ & $5.6 \pm 2.4$ & $5.3 \pm 2.0$ & $5.4 \pm 1.8$ \\
\hline Female patients, $\%$ & $57.4 \pm 12.8$ & $54.2 \pm 13.5$ & $55.7 \pm 13.7$ \\
\hline Starting TNA value & $11.7 \pm 10.7$ & $4.4 \pm 5.0$ & $4.1 \pm 4.1$ \\
\hline
\end{tabular}




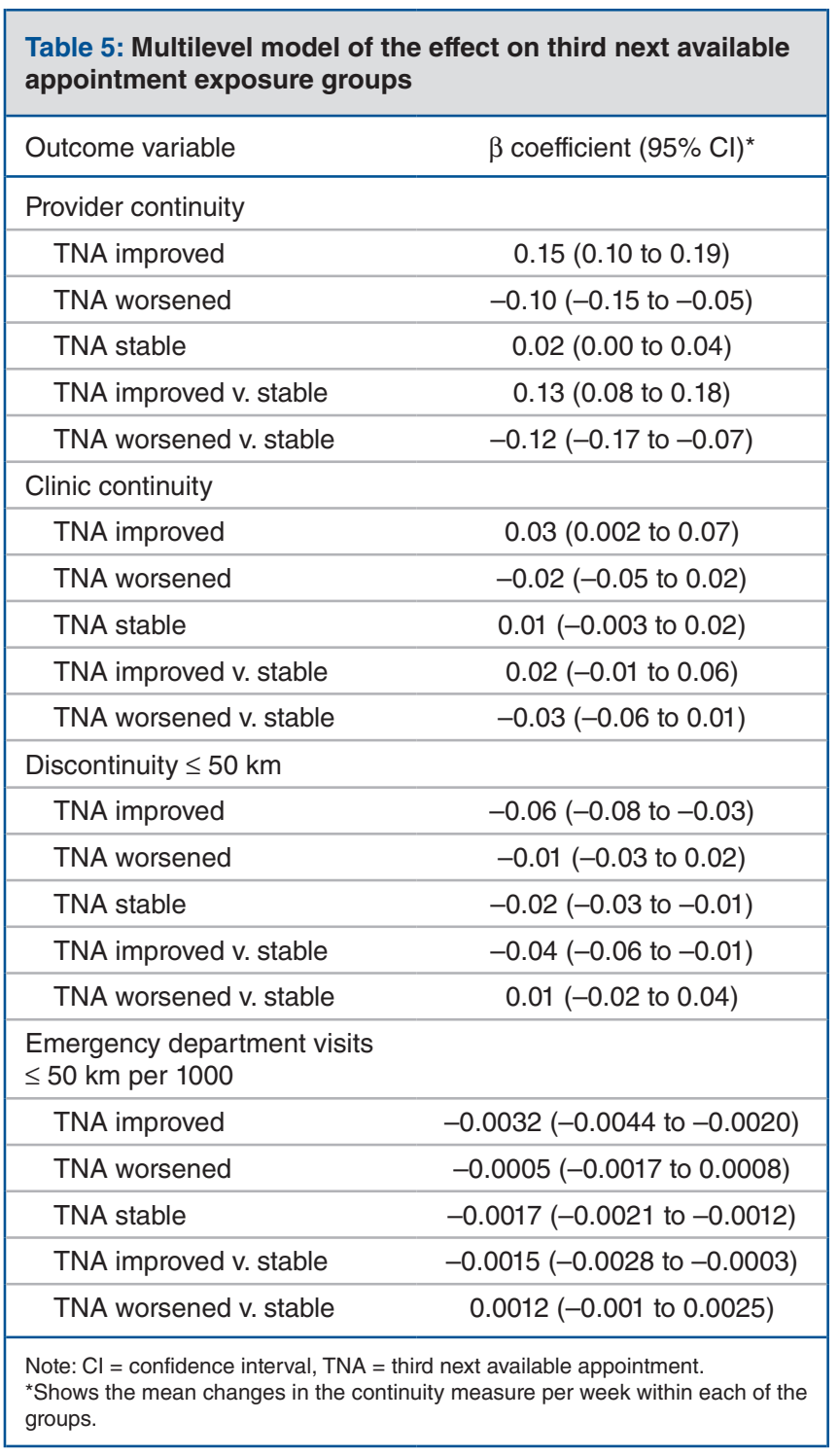

appointment delay and reduced continuity of care, our team plans to continue to explore this linkage in future work. We assert that a singular focus on continuity of care as the key to good patient outcomes without an understanding of how access influences continuity of care is shortsighted. High provider continuity may be the desired intended outcome, but it cannot be achieved without addressing access issues or understanding how access contributes to obtaining appropriate continuity of care. Availability of the physician ensures a patient can seek care when it is needed, and with his or her own provider.

Our data show that changes in a physician's appointment delay were not associated with a change in clinic continuity. The office practice redesign philosophy operant in the Chinook Primary Care Network encourages each physician to "take care of your own," 49 so the option for patients to see another physician in the same clinic was typically not available. Contingency plans when the attached physician was away for more than a few days (e.g., on vacation) may include offering appointments with another physician practising in the clinic, but those situations reflect an exception.

Other investigators have explored the relations between access and continuity of care, ${ }^{16,25,38,39,45,50-60}$ access and emergency department use, ${ }^{16,61-72}$ and continuity of care and emergency

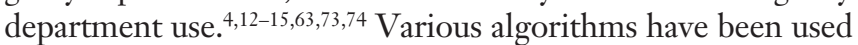
to develop virtual panels to associate patient to activity to specific physicians. ${ }^{12,14,33,36,75}$ In the majority of these studies, access $^{25,38,50-53,56,59,60,62,64,67-72,75}$ and continuity of care and emergency department use $25,38,50-53,56,59,60,62,64,66-72,75$ were inferred through self-report in patient surveys. Although these studies provide valuable insight into the topic area, using a standardized metric like TNA appointment measured over 8 years and using physicians' actual panel that directly links the activity of their patients seeking primary care services allowed us to explore how changing availability to physicians influences where patients seek their care.

Confidence in our findings is strengthened by the use of multilevel regression models that accounted for within-year and within-week clustering for each physician. Furthermore, the longitudinal nature of our study gives us confidence that the findings about the relation between access and continuity of care are robust; they are based on an analysis of data that incorporated seasonal variation, health care system turbulence, and changes at the physician and panel level over a period of 8 years.

Our study confirms a long-held assumption that continuity of care and access are not independent concepts. Some jurisdictions have reported unintended consequences on continuity of care when access is given precedence; we assume that the opposite may be true when continuity of care, especially relational continuity of care, is given precedence over appropriate access. In this era of public expectations of instant access, there has been a proliferation of walk-in-style clinics and smartphone apps that threaten continuity of care. Primary care access is a critical consideration in the provision of high-quality and effective health care; however, its balance with continuity of care should not be overlooked.

Physicians cannot be available at all times, so it is reasonable to posit that physician-led team-based care in the patient's medical home is a plausible strategy to increase access to a consistent team and, subsequently, continuity of care. Metrics that can assess "team continuity" should be developed. The culture and funding of primary care needs to shift in ways that support continuity of care at the team level and manage patient expectations around who on the team can best meet the presenting need.

In this study, we focused on identifying physicians who improved, worsened or maintained their level of access within a given year; we did not address the rate of change or the different levels of access within the stable group (e.g., physicians who maintained same-day or next-day access throughout the year compared to those who maintained $\geq 20$-d access). Our team plans to conduct studies to address these topics and attempt to determine the optimal access threshold within primary care. 


\section{Limitations}

A limitation of this study was its restriction to 1 primary care network that does not serve a large metropolitan centre where more service options (e.g., walk-in clinics) may be available. The observed relation between TNA appointment and provider continuity will undoubtedly be more complex in the presence of other care alternatives. However, our findings are still generalizable to other parts of Alberta and to other Canadian provinces; if access to the physician is appropriate from the patient's perspective, provider continuity will be maintained. The longitudinal measurement of TNA and the data generated by using annual panels allowed us to explore this relation in greater detail.

It is unclear whether the increased emergency department use observed may equate to a deteriorating condition; rather, it may reflect a convenient source of primary care.

The TNA metric we chose to infer access may also be a limitation of our study. We recognize that access to primary care is a large concept that includes both having a physician and getting access to that physician's services. The TNA metric is limited to the delay the patient experiences when attempting to book an appointment with his or her physician. Since its value can be obtained only by viewing the physician's schedule at a specific day and time each week, there is no way to verify its accuracy. However, in our study, TNA appointments were measured for quality-improvement purposes, and because no TNA targets were mandated, they were not likely to be gamed; we are thus reasonably confident that the TNA measures used are a valid inference of delay. Nevertheless, other jurisdictions have failed to implement TNA measurement successfully. We concede that implementing TNA measurement would be difficult if the concept of TNA was introduced without the support of an office practice redesign learning collaborative.

We used statistical significance and trajectory direction to define our TNA exposure groups to decrease the uncertainty regarding an annual change. If we had relied only on the steepness of the trajectory, we may have run the risk of classifying TNA as improving or worsening inappropriately. Within the stable TNA trajectory group, most physicians had a $p>0.2$. The certainty around appropriate physician classification in the exposure category would have been low for many of these slopes if we had not taken into account the $p$ value.

\section{Conclusion}

Our findings suggest that changing appointment delay in primary care can influence how patients choose to use the health care system. Furthermore, it can affect provider continuity, discontinuity and emergency department use, which, in turn, can affect health and system outcomes. As Alberta and other jurisdictions reform their health care systems to ensure patients receive appropriate care in the community, focusing on reducing delay in obtaining appointments with physicians practising in the community should be considered as a focal point of primary care form. However, improving access to primary care should be not done at the expense of continuity of care.

\section{References}

1. The 2017-2020 Health Plan and Business Plan. A healthier future. Together. Edmonton: Alberta Health Services; 2019:1-35.

2. Starfield B. Continuous confusion? Am 7 Public Health 1980;70:117-9.

3. Wall EM. Continuity of care and family medicine: definition, determinants, and relationship to outcome. F Fam Pract 1981;13:655-64.

4. Tammes P, Purdy S, Salisbury C, et al. Continuity of primary care and emergency hospital admissions among older patients in England. Ann Fam Med 2017;15:515-22

5. Jung B, Cho KH, Lee DH, et al. The effects of continuity of care on hospital utilization in patients with knee osteoarthritis: analysis of nationwide insurance data. BMC Health Serv Res 2018;18:152.

6. Barker I, Steventon A, Deeny SR. Association between continuity of care in general practice and hospital admissions for ambulatory care sensitive conditions: cross sectional study of routinely collected, person level data. BMF 2017; 356:(j84).

7. Cho KH, Lee SG, Jun B, et al. Effects of continuity of care on hospital admission in patients with type 2 diabetes: analysis of nationwide insurance data. BMC Health Serv Res 2015;15:107.

8. Bayliss EA, Ellis JL, Shoup JA, et al. Effect of continuity of care on hospital utilization for seniors with multiple medical conditions in an integrated health care system. Ann Fam Med 2015;13:123-9.

9. Bazemore A, Petterson S, Peterson LE, et al. Higher primary care physician continuity is associated with lower costs and hospitalizations. Ann Fam Med 2018;16:492-7.

10. Kao $\mathrm{YH}, \mathrm{Wu} \mathrm{S}$. Is continuity of care associated with avoidable hospitalization among older asthmatic patients? Medicine 2016;95:e4948.

11. Nyweide DJ, Anthony DL, Bynum JPW, et al. Continuity of care and the risk of preventable hospitalization in older adults. 7AMA Intern Med 2013;173: $1879-85$.

12. Ionescu-Ittu R, McCusker J, Ciampi A, et al. Continuity of primary care and emergency department utilization among elderly people. CMAf 2007;177: 1362-8.

13. Bentler SE, Morgan RO, Virnig BA, et al. The association of longitudinal and interpersonal continuity of care with emergency department use, hospitalization, and mortality among Medicare beneficiaries. PLoS One 2014;9:e115088.

14. Gill JM, Mainous AG 3rd, Nsereko M. The effect of continuity of care on emergency department use. Arch Fam Med 2000;9:333-8.

15. Katz DA, McCoy KD, Vaughan-Sarrazin MS. Does greater continuity of Veterans' Administration primary care reduce emergency department visits and hospitalization in older veterans? 7 Am Geriatr Soc 2015;63:2510-8.

16. Yoon J, Cordasco KM, Chow A, et al. The relationship between same-day access and continuity in primary care and emergency department visits. PLoS One 2015; 10: e0135274.

17. Fenton JJ, Franks P, Reid RJ, et al. Continuity of care and cancer screening among health plan enrollees. Med Care 2008;46:58-62.

18. Arnold LD, McGilvray MMO, Cooper JK, et al. Inadequate cancer screening: lack of provider continuity is a greater obstacle than medical mistrust. 7 Health Care Poor Underserved 2017;28:362-77.

19. Blewett LA, Johnson PJ, Lee B, et al. When a usual source of care and usual provider matter: adult prevention and screening services. 7 Gen Intern Med 2008;23:1354-60.

20. Poole B, Gelmon K, Kan L. Is Canadian women's breast cancer screening behaviour associated with having a family doctor? Can Fam Physician 2010;56:e150-7.

21. Dossa AR, Moisan J, Guenette L, et al. Association between interpersonal continuity of care and medication adherence in type 2 diabetes: an observational cohort study. CMA7 Open 2017;5:E359-64.

22. Hansen RA, Voils CI, Farley JF, et al. Prescriber continuity and medication adherence for complex patients. Ann Pharmacother 2015;49:293-302.

23. Warren JR, Falster MO, Tran B, et al. Association of continuity of primary care and statin adherence. PLoS One 2015;10: e0140008.

24. Fan VS, Burman M, McDonell MB, et al. Continuity of care and other determinants of patient satisfaction with primary care. 7 Gen Intern Med 2005;20: 226-33.

25. Wetmore S, Boisvert L, Graham E, et al. Patient satisfaction with access and continuity of care in a multidisciplinary academic family medicine clinic. Can Fam Physician 2014;60:e230-6.

26. De Maeseneer JM, De Prins L, Gosset C, et al. Provider continuity in family medicine: Does it make a difference for total health care costs? Ann Fam Med $2003 ; 1: 144-8$

27. Hollander MJ, Kadlec H. Financial implications of the continuity of primary care. Perm 7 2015;19:4-10.

28. Gulliford M, Figueroa-Munoz J, Morgan M, et al. What does 'access to health care' mean? 7 Health Serv Res Policy 2002;7:186-8.

29. A vision for Canada: family practice - the patient's medical home. Ottawa: College of Family Physicians of Canada; 2011.

30. Benett IJ. Access, continuity, or both. Br 7 Gen Pract 2014;64:388-9.

31. Tammes P, Salisbury C. Continuity of primary care matters and should be protected. BM7 2017;365:j373.

32. Primary health care. Edmonton: Government of Alberta; 2019. Available: www.alberta.ca/primary-health-care.aspx\#toc-3 (accessed 2019 Nov. 14). 
33. Murray M. Patient care: access. BM7 2000;320:1594-6.

34. Cook LL, Gelber T, Cook CM. Implementation of a physician-patient attachment initiative in Alberta. Healthc Q 2019;22:40-6.

35. Murray M, Berwick DM. Advanced access: reducing waiting and delays in primary care. 7AMA 2003;289:1035-40.

36. Ejlertsson G, Berg S. Continuity of care in health care teams. A comparison of continuity measures and organisational solutions. Scand 7 Prim Health Care $1985 ; 3: 79-85$.

37. Branch HS, editor. Calculating distances in Alberta. no 4 of Geographic methodology series. Edmonton: Alberta Health and Wellness; 2004.

38. Haggerty J, Pineault R, Beaulieu MD, et al. Accessibility and continuity of primary care in Quebec. Ottawa: Canadian Health Services Research Foundation; 2004.

39. Balasubramanian H, Banerjee R, Denton B, et al. Improving clinical access and continuity through physician panel redesign. 7 Gen Intern Med 2010;25:1109-15.

40. Murray M, Davies M, Boushon B. Panel size: How many patients can one doctor manage? Fam Pract Manag 2007;14:44-51.

41. Keane D, Woodward CA, Ferrier BM, et al. Female and male physicians: different practice profiles: Will increasing numbers of female GPs affect practice patterns of the future? Can Fam Physician 1991;37:72-81.

42. Bertakis KD, Franks P, Azari R. Effects of physician gender on patient satisfaction. 7 Am Med Womens Assoc (1972) 2003;58:69-75.

43. Weeks WB, Wallace AE. Rural-urban differences in primary care physicians' practice patterns, characteristics, and incomes. 7 Rural Health 2008;24:161-70.

44. Kasteler J, Kane RL, Olsen DM, et al. Issues underlying prevalence of "doctorshopping" behavior. 7 Health Soc Behav 1976;17:329-39.

45. Panattoni L, Stone A, Chung S, et al. Patients report better satisfaction with part-time primary care physicians, despite less continuity of care and access. $\mathcal{F}$ Gen Intern Med 2015;30:327-33.

46. Salisbury C, Johnson L, Purdy S, et al. Epidemiology and impact of multimorbidity in primary care: a retrospective cohort study. Br 7 Gen Pract 2011;61:e12-21.

47. Wang Y, Hunt K, Nazareth I, et al. Do men consult less than women? An analysis of routinely collected UK general practice data. BMF Open 2013;3: e003320.

48. CIHI's population grouping methodology 1.0. Ottawa: Canadian Institute for Health Information; 2016.

49. Salisbury C, Sampson F, Ridd M, et al. How should continuity of care in primary health care be assessed? Br 7 Gen Pract 2009;59:e134-41.

50. Bower P, Roland M, Campbell J, et al. Setting standards based on patients' views on access and continuity: secondary analysis of data from the general practice assessment survey. BM7 2003;326:258-63.

51. Ehman KM, Deyo-Svendsen M, Merten Z, et al. How preferences for continuity and access differ between multimorbidity and healthy patients in a team care setting. 7 Prim Care Community Health 2017;8:319-23.

52. Forrest CB, Starfield B. Entry into primary care and continuity: the effects of access. Am 7 Public Health 1998;88:1330-6.

53. Haggerty JL, Pineault R, Beaulieu MD, et al. Practice features associated with patient-reported accessibility, continuity, and coordination of primary health care. Ann Fam Med 2008;6:116-23.

54. Hung D, Chung S, Martinez M, et al. Effect of organizational culture on patient access, care continuity, and experience of primary care. 7 Ambul Care Manage 2016;39:242-52.

55. Nelson K, Sun H, Dolan E, et al. Elements of the patient-centred medical home associated with health outcomes among veterans: the role of primary care continuity, expanded access, and care coordination. 7 Ambul Care Manage 2014;37:331-8.

56. Raivio R, Jääskeläinen J, Holmberg-Marttila D, et al. Decreasing trends in patient satisfaction, accessibility and continuity of care in Finnish primary health care - a 14-year follow-up questionnaire study. BMC Fam Pract 2014;15:98.

57. Stange KC. Tension between access and continuity. Ann Fam Med 2011;9:85.

58. Guthrie B, Wyke S. Personal continuity and access in UK general practice: a qualitative study of general practitioners' and patients' perceptions of when and how they matter. BMC Fam Pract 2006;7:11.

59. Wong ST, Regan S. Patient perspectives on primary health care in rural communities: effects of geography on access, continuity and efficiency. Rural Remote Health 2009;9:1142.

60. Rosland AM, Krein SL, Kim HM, et al. Measuring patient-centered medical home access and continuity in clinics with part-time clinicians. Am 7 Manag Care 2015;21:e320-8.

61. Basu S, Phillips RS. Reduced emergency department utilization after increased access to primary care. PLoS Med 2016;13:e1002114.

62. Cowling TE, Harris $M$, Watt H, et al. Access to primary care and the route of emergency admission to hospital: retrospective analysis of national hospital administrative data. BM7 Qual Saf 2016;25:432-40.

63. Tammes P, Purdy S, Salisbury C, et al. Can continuity of primary care decrease emergency care use? A nested case-control study. Lancet 2016;388 (Suppl 2):S13.
64. van den Berg MJ, van Loenen T, Westert GP. Accessible and continuous primary care may help reduce rates of emergency department use. An international survey in 34 countries. Fam Pract 2016;33:42-50.

65. Whittaker W, Anselmi L, Kristensen R, et al. Associations between extending access to primary care and emergency department visits: a difference-indifferences analysis. PLoS Med 2016;13:e1002113.

66. Blank FS, Li H, Henneman PL, et al. A descriptive study of heavy emergency department users at an academic emergency department reveals heavy ED users have better access to care than average users. F Emerg Nurs 2005;31:139-44.

67. Cowling TE, Cecil EV, Soljak MA, et al. Access to primary care and visits to emergency departments in England: a cross-sectional, population-based study. PLoS One 2013;8:e66699.

68. Harris MJ, Patel B, Bowen S. Primary care access and its relationship with emergency department utilisation: an observational, cross-sectional, ecological study. Br 7 Gen Pract 2011;61:e787-93.

69. Howard M, Goertzen J, Kaczorowski J, et al. Emergency department and walk-in clinic use in models of primary care practice with different after-hours accessibility in Ontario. Healthc Policy 2008;4:73-88.

70. MacKichan F, Brangan E, Wye L, et al. Why do patients seek primary medical care in emergency departments? An ethnographic exploration of access to general practice. BM7 Open 2017;7:e013816.

71. Mian O, Pong R. Does better access to FPs decrease the likelihood of emergency department use? Results from the Primary Care Access Survey. Can Fam Physician 2012;58:e658-66.

72. Weisz D, Gusmano MK, Wong G, et al. Emergency department use: A reflection of poor primary care access? Am J Manag Care 2015;21:e152-60.

73. Chaiyachati KH, Gordon K, Long T, et al. Continuity in a VA patientcentered medical home reduces emergency department visits. PLoS One 2014, 9:e96356.

74. Nyweide DJ, Bynum JP. Relationship between continuity of ambulatory care and risk of emergency department episodes among older adults. Ann Emerg Med 2017;69:415.e3

75. Cecil E, Bottle A, Cowling TE, et al. Primary care access, emergency department visits, and unplanned short hospitalizations in the UK. Pediatrics 2016; 137:e20151492.

Affiliations: Applied Research \& Evaluation Services, Primary Health Care (L. Cook, C. Cook), Alberta Health Services; Faculty of Health Sciences (L. Cook, Spenceley), University of Lethbridge, Lethbridge, Alta.; Applied Research \& Evaluation Services, Primary Health Care (Golonka), Alberta Health Services, Edmonton, Alta.; Applied Research \& Evaluation Services, Primary Health Care (Walker), Alberta Health Services; Cumming School of Medicine (Walker, Faris), University of Calgary; Health Services Statistical \& Analytics Methods, Analytics, Data Integration, Measurement \& Reporting (Faris), Alberta Health Services, Calgary, Alta.; Enhancing Care in the Community (Lewanczuk), Alberta Health Services; Department of Medicine (Lewanczuk), University of Alberta, Edmonton, Alta.; Chinook Primary Care Network (Wedel, Byers, Collins); Primary Health Care Integration Network (Love), Alberta Health Services; Public \& Primary Health Care (Andres), Alberta Health Services, Lethbridge, Alta.; Applied Research \& Evaluation Services, Primary Health Care (Oddie), Alberta Health Services, Red Deer, Alta.; Faculty of Social Sciences (Oddie), University of Calgary, Calgary, Alta.

Contributors: Lisa Cook, Richard Golonka, Charles Cook and Scott Oddie were responsible for the conception and design of the study. Lisa Cook, Richard Golonka, Charles Cook, Robin Walker, Peter Faris, Rebecca Love and Scott Oddie were involved in data analysis and interpretation. Lisa Cook drafted the manuscript, and Richard Golonka, Charles Cook, Robin Walker, Peter Faris, Shannon Spenceley, Richard Lewanczuk, Robert Wedel, Rebecca Love, Cheryl Andres, Susan Byers, Tim Collins and Scott Oddie revised it for important intellectual content. All of the authors approved the final version to be published and agreed to be accountable for the work.

Data sharing: The data are not available for use by other researchers.

Acknowledgement: The authors thank Tony Mottershead for his thoughts and suggestions during the planning phase of this study.

Supplemental information: For reviewer comments and the original submission of this manuscript, please see www.cmajopen.ca/content/8/4/ E722/suppl/DC1. 